\title{
Forced use therapy to improve hand function in spastic cerebral palsy children
}

\author{
*C Elanchezhian ${ }^{1}$, P SwarnaKumari ${ }^{2}$ \\ Sri Lanka Journal of Child Health, 2020; 49(4): 335-340
}

\begin{abstract}
Introduction: Prehension, the ability to grasp, hold and manipulate objects is an important hand function. Impairment in hand function makes it difficult to fulfill activities of daily living.
\end{abstract}

Objectives: To assess the effect of forced use therapy (FUT) in improving hand function of hemiplegic cerebral palsy children.

Outcome measures: Modified Ashworth scale, Fegl Meyer assessment upper extremity, 9-hole peg board, upper extremity functional index and caregiver functional use survey are the outcome measures.

Method: Fifty two children with cerebral palsy were divided into 2 groups A and B, 26 in each group. Group A was given conventional hand function exercise whilst group B was given forced hand use therapy. Both groups received treatment for 45 minutes for the affected limb for 5 days a week. However, the FUT group was administered with gloves to constraint the hand movement for 6 hours daily. They were administered with the protocol for 4 weeks and outcomes were measured pre- and post-treatment duration.

Results: FUT showed significantly better improvement over the conventional group in outcome measures $(\mathrm{p}<0.05)$

Conclusions: FUT caused reduction in spasticity and increased functional ability in children with spastic hemiplegic cerebral palsy.

${ }^{1}$ Research Scholar, ${ }^{2}$ Associate Professor,
Department of Rehabilitation Science, Holy Cross
College, Affiliated to Bharathidasan University,
Tiruchirapalli, Tamil Nadu, India.
*Correspondence: elanchezhianrehab@gmail.com
iD orcid.org/0000-0002-5408-4030

(Received on 14 December 2019: Accepted after revision on 24 January 2020)

The authors declare that there are no conflicts of interest

Personal funding was used for the project.

Open Access Article published under the Creative

Commons Attribution CC-BY (c) (P)
DOI: http://dx.doi.org/10.4038/sljch.v49i4.9264

(Key words: Cerebral palsy, spasticity, hemiplegia, hand function, forced use therapy)

\section{Introduction}

Cerebral palsy (CP) differs in clinical presentation and severity of impairment ${ }^{1}$. $\mathrm{CP}$ is the most common cause of childhood disability and is seen in 2-2.5 per 1,000 births ${ }^{2}$. According to studies, $29 \%$ of children with CP have hemiplegia ${ }^{3}$. Evolutionary thumb specialization as an opposing digit makes it vital in that it provides exceptional motor skills ${ }^{4}$. Affected kids can have thumb adduction and/or flexion with limited wrist extension, as well as more proximal abnormalities of upper limb tone, posture, and function affecting usage of hand ${ }^{5}$. Many daily activities require the hands to carry out various movements simultaneously in a coordinated manner ${ }^{5}$.

Spasticity is the most common symptom in CP. Spasticity may cause problems with gait, feeding, washing, toilet use and dressing ${ }^{6}$. CP impairs motor function and eventually causes osteo-articular malformation ${ }^{7}$. Upper limb training involves purposeful outdoor training activities. This is supported by motor control and motor learning theories ${ }^{8}$. Forced use therapy (FUT) is a recovery technique intended to force the use of the most impaired limb through rigorous application of taskoriented behavioural exercises and was originally developed for upper extremity stroke rehabilitation ${ }^{9}$. FUT is similar to constraints induced movement therapy. An aim of FUT is encouraging spontaneous use of affected limb in daily activities ${ }^{10}$.

\section{Objectives}

To assess the effect of FUT in improving hand function in hemiplegic cerebral palsy children.

\section{Method}

Outcome tools

- Modified Ashworth scale: This is an important test in rehabilitation for physical examination of spasticity ${ }^{7}$.

- Fegl Meyer assessment upper extremity (FMA-UE): This tool assesses the upper extremity sensorimotor function ${ }^{11}$.

- 9-hole peg board: This tool is used in measuring unilateral dexterity of the 
finger to determine the extent of fine motor impairment in people with functional performance difficulties ${ }^{12}$.

- $\quad$ Upper extremity functional index (UEFI): This is used in individuals with hand and upper extremity disorders to measure upper extremity function. This distinguishes between "Extent of limitations" and "Quality of Life" categories $^{13}$.

- Caregiver functional use survey: Bimanual tasks and scoring guidelines in the caregiver survey are used for measuring the frequencies of usage of children's upper extremity in real-life situations $^{14}$.

Inclusion Criteria ${ }^{3}$ : Both left and right spastic hemiplegia, both male and female children, children with age between 4-12 years, Modified Ashworth scale 4-1 and Classification-hemiplegia using Manual ability classification system (MACS) I to III.

Exclusion Criteria: Classification -hemiplegia, MACS IV to V children, deformity in hand, antispasmodic drugs, children undergone surgical procedure in hand ${ }^{15}$.
Procedure: Study was carried out at the Department of Rehabilitation Sciences, Holy Cross College, Tiruchirapalli, after research ethical approval. Trial registration number TCTR 20191211003. For this research, children were chosen, diagnosed with spastic hemiplegic and met the requirements for inclusion criteria. Informed consent was obtained from the parents or guardians of children before commencement of study, educating them regarding the benefits and adverse effects that might be caused by the treatment.

For the study, a total of 67 subjects with spastic hemiplegia were assessed physically among which 11 were excluded and 4 were unwilling to participate in the study. Fifty two children with left or right hemiplegia were recruited for the study randomly. They were divided into two groups A and B with 26 subjects in each group. Group A was administered conventional therapy and Group B was administered FUT.

Conventional group (Group A): Children were given hand function activities for both hands without any constraint ${ }^{8}$. Conventional therapy was administered for 45 minutes as directed.

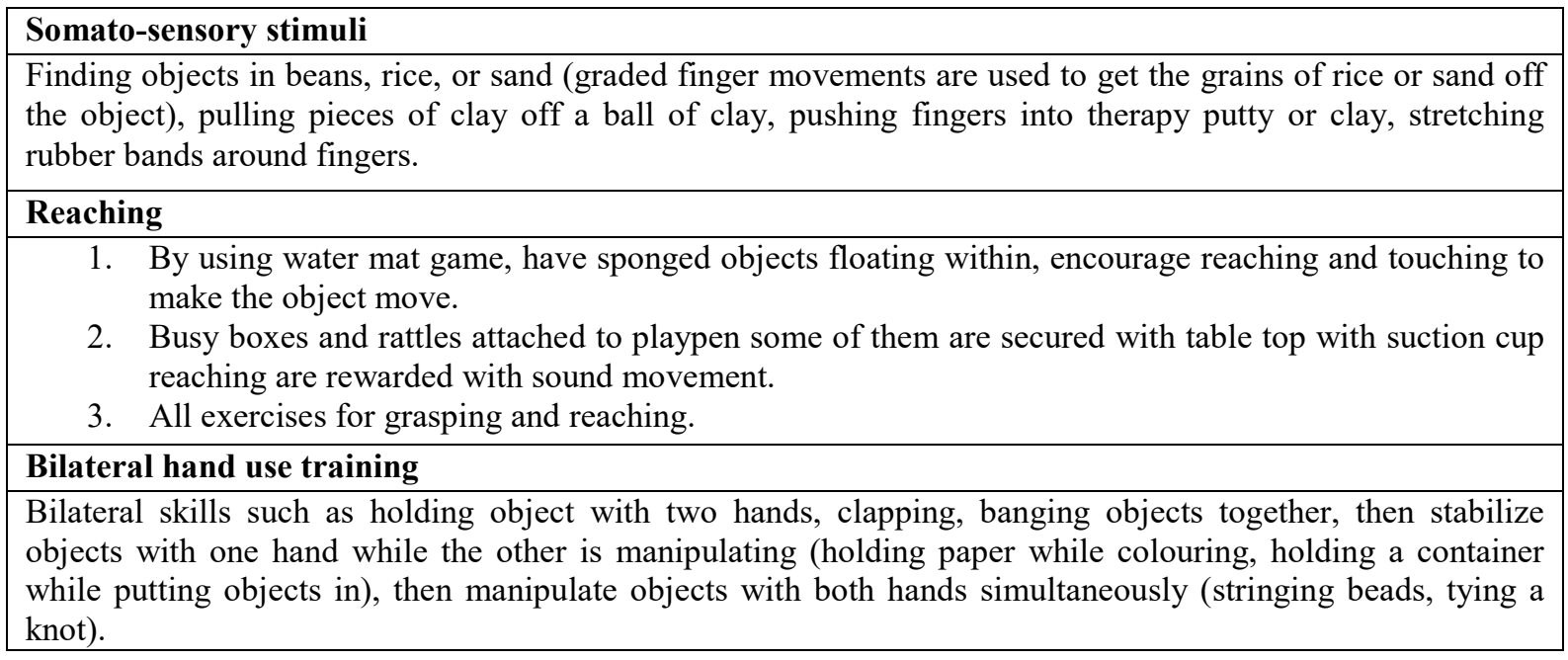

Experimental group (Group B): A glove was used to restrain the child's less affected upper extremity and the sling was secured with a belt to his/her body ${ }^{16}$. Forced used during the weekend intervention were not given but still the hands were restrained for 6 hours where the child does all the functional activity with the affected hand. The intervention consisted of play and self-care activities to enable the child to practise the use of the most affected upper extremity (Figures 1 and 2 ). Child is given hand manipulation and prehension movements for 45 minutes for affected hand. Movements and activities were focused only on affected hand. The following activities were included and monitored closely to analyse the performance 


\begin{tabular}{|l|}
\hline Gross motor - activities \\
\hline $\begin{array}{l}\text { Elbow flexion and extension, Forearm pronation and supination, Wrist flexion and extension, Wrist ulnar } \\
\text { deviation and radial deviation, Fingers flexion and extension, Finger numbering, Opposition of thumb. }\end{array}$ \\
\hline Fine motor -activities \\
\hline $\begin{array}{l}\text { Moving beans from one cup to another, Putting pegs in a pegboard, Squeezing a stress ball, Stacking } \\
\text { pennies, Rubber band stretching with fingers Knobs \& Screws- clock wise and anti-clock wise, Clip clothes } \\
\text { pins or kitchen clips to the edge of a container. Spreading of fingers apart, Roll ball from tip of fingers to } \\
\text { palm on a table. }\end{array}$ \\
\hline
\end{tabular}

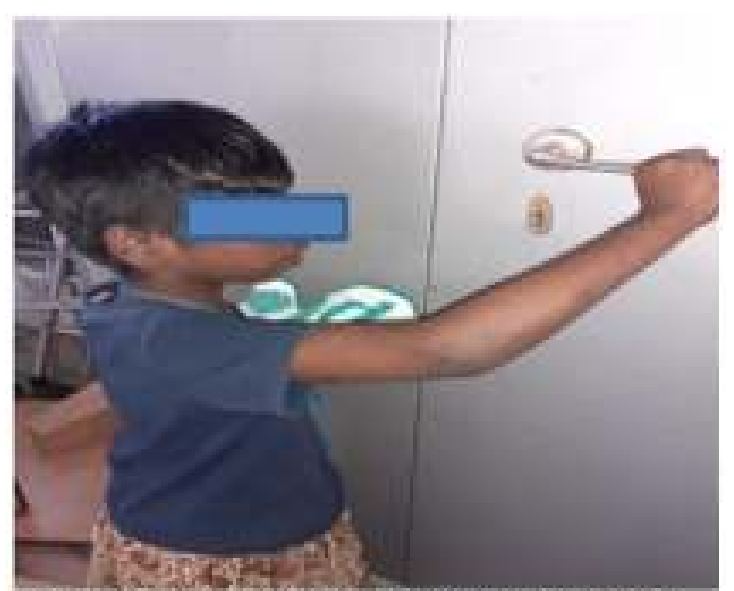

Figure 1: Screws clockwise and anti-clockwise "Permission given by parents to pablish photograph

Both groups were administered hand function activities for six hours per day, 5 days per week for 4 weeks.

\section{Results}

Statistical analysis was done utilising the SPSS version 21. Values were presented as mean $\pm \mathrm{SD}$; paired Student t-test was used to analyse the efficacy of pre- and post-treatment values of modified Ashworth scale, FMA-UE, 9-hole pegboard, UEFI, caregiver functional use survey. Significant $\mathrm{p}$ value was considered to be $<0.05$. Fifty two children with hemiplegic $\mathrm{CP}$ were recruited for the study.

Descriptive data of the conventional and experimental groups are shown in Table 1.

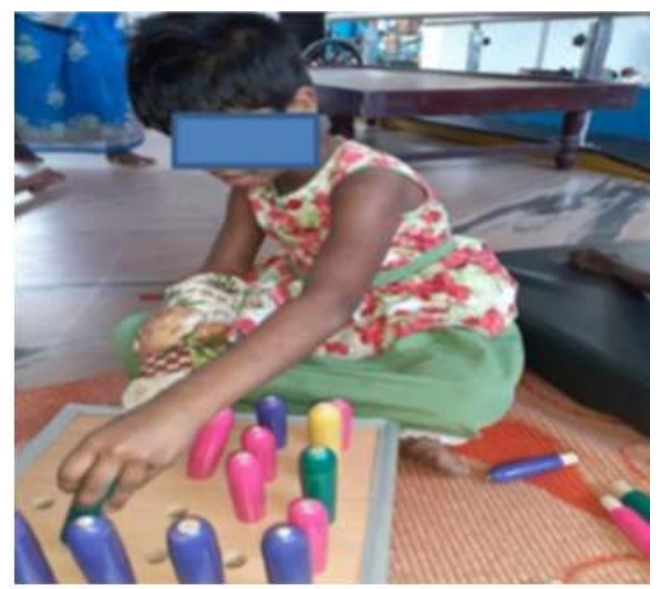

Figure 2: Arranging pegs in a pegboard *Permission given by parents to publish photograph

Comparison of conventional and experimental groups is shown in Table 2. To compare the pre and post values of conventional group and experimental group, paired sample t-test was used and to compare Ashworth scale scores among groups, the Wilcoxon signed rank test was applied

Comparison between conventional and experimental group is shown in Table 3. Analysis of co-variance is used to compare the mean value of experimental and control groups of all the variables including pre measurement as a covariate to nullify the initial effect. The results of all the variables show there is a significant improvement in the experimental group when compared with the conventional group.

Table 1: Descriptive data of the conventional and experimental groups $(n=52)$

\begin{tabular}{|l|c|c|c|c|}
\hline \multicolumn{1}{|c|}{ Groups } & \multicolumn{2}{c|}{ Sex } & \multicolumn{2}{c|}{ Age } \\
\hline & Male & Female & Mean & 2.38 \\
\hline Conventional group & 10 & 16 & 7.08 & 2.70 \\
\hline Experimental group & 8 & 18 & 6.42 & \\
\hline
\end{tabular}


Table 2: Pre-test and Post-test values in different assessments in conventional and experimental groups

\begin{tabular}{|l|c|c|c|}
\hline \multicolumn{1}{|c|}{ Assessment } & $\begin{array}{c}\text { Pre-test value } \\
\text { Mean (SD) }\end{array}$ & $\begin{array}{c}\text { Post-test value } \\
\text { Mean (SD) }\end{array}$ & T value \\
\hline Fegl Meyer assessment upper limb & $37.64(8.52)$ & $40.44(8.87)$ & -9.00 \\
Conventional group & $42.23(8.24)$ & $55.96(7.28)$ & -10.70 \\
Experimental group & & & \\
\hline 9 hole peg board & $155.56(38.04)$ & $139.80(25.39)$ & 4.82 \\
Conventional group & $180.54(45.82)$ & $150.85(42.82)$ & 5.08 \\
Experimental group & & & \\
Upper extremity functional index & $30.56(12.25)$ & $33.76(11.97)$ & -12.71 \\
Conventional group & $24.54(7.47)$ & $38.42(9.26)$ & -8.38 \\
Experimental group & & & \\
Caregiver functional use survey & $95.82(16.06)$ & $102.60(17.32)$ & -8.35 \\
Conventional group & $86.98(8.25)$ & $107.55(8.76)$ & -15.38 \\
Experimental group & Pre-test value & Post-test value & $\mathbf{Z}$ value \\
\hline & Mean (SD) & Mean (SD) & \\
\hline Modified Ashworth scale & & & \\
Conventional group & $2.44(0.71)$ & $2.00(0.50)$ & -4.56 \\
Experimental group & $2.92(0.62)$ & $1.31(0.47)$ & -3.31 \\
\hline
\end{tabular}

Table 3: Comparison between conventional and experimental group

\begin{tabular}{|l|c|c|c|c|}
\hline \multicolumn{1}{|c|}{ Assessment } & Mean \pm SE & \multicolumn{2}{c|}{ 95\% confidence interval } & p-value \\
\cline { 3 - 5 } & & Lower Bound & Upper Bound & \\
\hline Fegl Meyer assessment upper limb & & & & \\
Conventional group & $42.31 \pm 0.92$ & 40.45 & 44.18 & 0.000 \\
Experimental group & $54.15 \pm 0.90$ & 52.32 & 55.98 & \\
\hline 9 hole peg board & & & & \\
Conventional group & $148.56 \pm 4.18$ & 140.15 & 156.96 & 0.003 \\
Experimental group & $142.56 \pm 4.09$ & 134.19 & 150.65 & \\
\hline Upper extremity functional index & & & & \\
Conventional group & $31.06 \pm 1.23$ & 28.58 & 33.55 & 0.000 \\
Experimental group & $41.01 \pm 1.20$ & 38.58 & 43.44 & \\
\hline Caregiver functional use survey & & & & \\
Conventional group & $98.18 \pm 1.17$ & 95.82 & 100.11 & 0.000 \\
Experimental group & $111.80 \pm 1.15$ & 109.48 & 114.11 & \\
\hline Modified Ashworth scale & & & & \\
Conventional group & $2.00 \pm 0.50$ & 1.79 & 2.21 & 0.000 \\
Experimental group & $1.31 \pm 0.47$ & 1.12 & 1.50 & \\
\hline
\end{tabular}

\section{Discussion}

In the current study, the differences in physical performance of FUT group by using FMA-UE, 9hole peg board, upper extremity functional index, care giver functional user survey and modified Ashworth scale were compared. Also the physical performances of the two groups were investigated before and after the treatment. From the comparison results, it was found that FUT group had significantly improved with higher scores $(\mathrm{p}<0.05)$.

Luigi Tesio et al. carried out a study on FUT to improve crouch gait in adult hemiplegics. They compared the effectiveness of FUT with no constraints exercise. The results of the study showed that there was an effective improvement for the patients who underwent 'forced use' exercise for the paretic lower $\operatorname{limb}^{17}$. Laurent
Ballaz et al conducted a study on postural asymmetry using FUT on spastic hemiplegic children. They carried out studies using an upper limb constraint for 3-week, 6 hours per day on 12 non-consecutive days. During the intervention, the children wore a sling on the non-involved upper limb. After FUT, upper limb functional scores improved significantly, and postural asymmetry tended to decrease, compared with the pre-therapy values ${ }^{10}$. Wen-Hsiu Yu et al proposed that FUT can be used on lower extremity on gait performance and mobility of post-acute stroke patients. They carried out a study comparing the conventional studies and FUT and the study was carried out for 2 weeks. After the conclusion of the study, they found that the outcome measures had improved in the gait performance and mobility. They concluded that FUT can be used to improve gait parameters ${ }^{9}$. Hammer AM et al conducted a study on adult 
stroke participants where one group received a standard rehabilitation programme with training of 5 days per week for 2 weeks as inpatients or outpatients. The FUT group also wore a restraining sling on the non-paretic arm with a target of 6 hours per day. After 3 months of follow up the subjects with restraint sling had remarkable improvement in their functional activities. They suggest that constraints can improve in paralytic patients $^{18}$.

\section{Conclusions}

FUT caused reduction in spasticity and increased functional ability in children with spastic hemiplegic cerebral palsy.

\section{References}

1. Rasool F, Memon AR, Kiyani MM, Sajjad AG. The effect of deep cross friction massage on spasticity of children with cerebral palsy: A double-blind randomised controlled trial. Journal of the Pakistan Medical Association 2017; 67(1): 87-91.

2. Chinnavan E, Swarnakumari P. Efficacy of cold therapy and passive stretching to improve gait in spastic diplegic cerebral palsy children. International Journal of Pediatrics 2019; 7(9): 10109-18.

3. Chiu H-C, Ada L. Constraint-induced movement therapy improves upper limb activity and participation in hemiplegic cerebral palsy: a systematic review. Journal of Physiotherapy 2016; 62: 1307. https://doi.org/10.1016/j.jphys.2016.05.01 3

PMid: 27323932

4. Dincer F, Samut G. Hand function, A Practical guide to assessment. 2014 Springer; 23-40.

https://doi.org/10.1007/978-1-4614-94492_2

5. Basu AP, Pearse J, Kelly S, Wisher V, Kisler J. Early intervention to improve hand function in hemiplegic cerebral palsy. Frontiers in Neurology 2015; 5:1-9. https://doi.org/10.3389/fneur.2014.00281 PMid: 25610423 PMCid: PMC4285072

6. Shamsoddini A, Amirsalari S, Hollisaz MT, Rahimnia A, Khatibi-Aghda A. Management of spasticity in children with cerebral palsy. Iranian Journal of Pediatrics 2014; 24 (4), 345-51.
7. Mirska A, Kułak W, Okurowska-Zawada B, Dmitruk E. Effectiveness of multiple botulinum toxin sessions and the duration of effects in spasticity therapy in children with cerebral palsy. Child's Nervous System 2019; 35:141-7. https://doi.org/10.1007/s00381-018-39236

PMid: 30058050 PMCid: PMC6341047

8. Azzam AM. Effect of hand function training on improvement of hand grip strength in hemiplegic cerebral palsy in children. Novel Physiotherapies 2012; 2(6): 1-5. https://doi.org/10.4172/21657025.100011 6

9. Yu W-H, Liu W-Y, Wong AMK, Wang TO, Li YO, Lien HY. Effect of forced use of the lower extremity on gait performance and mobility of post-acute stroke patients. Journal of Physical Therapy Science 2015; 27: 421-5. https://doi.org/10.1589/jpts.27.421 PMid: 25729182 PMCid: PMC4339152

10. Ballaz L, Huffenus AF, Lamarre C, Koclas L, Lemay M. Effect of forced use therapy on posture in children with hemiplegic cerebral palsy: a pilot study. Journal of Rehabilitation Medicine 2012; 44: 268-71.

https://doi.org/10.2340/16501977-0920 PMid: 22278090

11. Fugl Meyer Assessment - U". University of Gothenburg. Retrieved 6 October 2016.

12. Duff SV, Aaron DH, Gogola GR, ValeroCuevas FJ. Innovative evaluation of dexterity in paediatrics. Journal of Hand Therapy 2015; 28(2): 144-50. https://doi.org/10.1016/j.jht.2015.01.004 PMid: 25835255 PMCid: PMC4424153

13. Bos I, Wynia K, Drost G, Almansa J, Kuks JBM. The extremity function index (EFI), a disability severity measure for neuromuscular diseases: psychometric evaluation. Disability and Rehabilitation 2018; 40(13): 1561-8. https://doi.org/10.1080/09638288.2017.13 00690

PMid: 28291950

14. Greaves S, Imms C, Dodd K, Krumlindesundholm L. Assessing bimanual performance in young children with hemiplegic cerebral palsy: a systematic 
review. Developmental Medicine and Child Neurology 2010; 52: 413-21. https://doi.org/10.1111/j.14698749.2009.0 3561.x

PMid: 20059510

15. Matusz PJ, Alexandra P, Key AP, Gogliotti SJ, Auld ML, Murray MM, Maitre NL. Somatosensory plasticity in paediatric cerebral palsy following constraint-induced movement therapy. Hindawi Neural Plasticity Volume 2018, Article ID 1891978, 14 pages. https://doi.org/10.1155/2018/1891978 PMid: 30532772 PMCid: PMC6250030

16. Elanchezhian C, Swarna Kumari P. Mirror therapy to improve hand function in spastic cerebral palsy children. International Journal of Research in Pharmaceutical Sciences 2019; 10(3), 2381-7.

https://doi.org/10.26452/ijrps.v10i3.1483
17. Tesio L, Rota V, Malloggi C, Brugliera L, Catino L. Crouch gait can be an effective form of forced-use/no constraint exercise for the paretic lower limb in stroke. International Journal of Rehabilitation Research 2017; 40:254-67.

https://doi.org/10.1097/MRR.0000000000 000236

PMid: 28574860 PMCid: PMC5555972

18. Hammer AM, Lindmark B. Effects of forced use on arm function in the subacute phase after stroke: A randomized, clinical pilot study. Physical Therapy 2016; 89(6), 526-39.

https://doi.org/10.2522/ptj.20080017

PMid: 19372172 